\title{
Direct Determination of Polychlorinated-Biphenyls in Automotive Shredder Residues by Gas Chromatography-Mass Spectrometry
}

\author{
María de los Desamparados Escribano Otero ${ }^{1}$, Mohamed Nour Kayali Sayadi ${ }^{1}$, Luis María Polo Díez ${ }^{2}$ \\ ${ }^{1}$ Mass Spectrometry Unit, Faculty of Chemistry, Complutense University of Madrid, Madrid, Spain; ${ }^{2}$ Department of Analytical \\ Chemistry, Faculty of Chemistry, Complutense University of Madrid, Madrid, Spain. \\ Email: kayali@ucm.es
}

Received March 26 $6^{\text {th }}, 2013$; revised April 25 $5^{\text {th }}, 2013$; accepted May 21 ${ }^{\text {st }}, 2013$

Copyright (C) 2013 M. D. Escribano Otero et al. This is an open access article distributed under the Creative Commons Attribution License, which permits unrestricted use, distribution, and reproduction in any medium, provided the original work is properly cited.

\begin{abstract}
An easy and rapid method is proposed for the determination of PCBs in automotive shredder residues, using gas chromatography combined with low resolution mass spectrometry (GC-MS). It is based on direct n-hexane solid-liquid extraction, subtracting background of the lineal aliphatic hydrocarbon interferences and integration of chromatographic peaks containing selected ion PCBs masses $(256,292$ and $326 \mathrm{~m} / \mathrm{z}$ ), which are common in all PCBs formulations. Recoveries were in the $80 \%-120 \%$ range; PCBs were detected and quantified in shredder samples from an automotive shredder industry, thus indicating the validity of the method.
\end{abstract}

Keywords: PCBs; Solid-Liquid Extraction; Automotive Shredder Residues; Gas Chromatography-Mass Spectrometry (GC-MS)

\section{Introduction}

Recycling of materials from manufactured products has become of increasing interest due to environmental problems involved being a challenge in modern sustainable development. In particular, automotive industry in European Community Countries generates thousands of tons per year whose recycling continues to be an essential research subject $[1,2]$.

The main basic steps of the automotive residue recycling process include crushing, flotation of plastics, rubber and glass, as well as aspiration of light particles; as a result of this process, two classic types of automotive residues have been differentiated; the metallic materials part has been largely recovered to be employed for different purposes; on the other hand, the so called "no metal or shredder organic residues part" has been less often recycled; it has sometimes been used to level land but more often it has been thrown on dumps [3]. However, it could be used as an energy source by combustion, for instance, in cement industries, which could increase recycling of these types of residues and moreover, it could replace fossil fuels [4]. For this purpose, it is necessary to know the potential presence of toxic precursor compounds in the shredder organic part, especially Polychlorinated Biphenyls (PCBs). These compounds have been used, as dielectric fluids in electrical capacitors, as stabilizers in engine oils and as plastic additives employed to manufacture a variety of automobile components [5]. They are very stable and resistant to chemicals and consequently, they are persistent in the environment, where their ubiquity is due to extensive use during the last century. These PCBs may give rise by combustion to even more toxic compounds such as benzofurans and dioxins, which are very unhealthy substances associated with serious illnesses [6]; these compounds have been detected in PCBs combustion at temperatures around $200^{\circ} \mathrm{C}[7,8]$. This fact makes it necessary for us to know the presence and concentration of such precursors in order to make an informed decision about the recycling of shredder organic residues by combustion.

Given the importance of PCBs, various matrixes have been analyzed to detect these compounds, including human food, accumulation in tissues, environmental pollution and oils [9-12]. To date, the analytical technique most often used to detect and quantify PCBs in environmental samples has been Gas Chromatography combined with high resolution Mass Spectrometry (GC-MS) in 
order to separate PCBs congeners. This technique obviously involves high instrumentation cost and technical skill [13]. In this research, a simple and rapid method based on direct solid-liquid extraction of PCBs from shredder organic residues and further total PCBs evaluation using low resolution GC-MS is proposed. It is based on background subtraction of the hydrocarbon noise over which PCBs chromatographic peaks appear and the use of selected characteristic PCBs ion masses (which are always present in chromatograms when shredder samples contains PCBs) along with integration of selected PCBs masses, without the need for a high resolution mass spectrometer. Method validity is established by recovery studies and shredder samples from a recycling automobile industry are analyzed.

\section{Materials and Methods}

\subsection{Equipment}

A Hewlett Packard gas chromatograph, model 5890 series 2 provided with a split/splitless injector and combined with a quadrupole mass spectrometer, model HP 5989A Engine as a detector; it is equipped with Hewlett-Packard Chemstation B.02.05 software which allows both correction of background over which chromatographic peaks appear and integration of selected ion masses. The column was a $5 \%$ dimethylphenylpolysiloxane, SLB-5MS, $30 \mathrm{~m} \times 0.25 \mathrm{~mm} \times 0.25 \mu \mathrm{m}$ film thickness. Helium VIP, supplied by Carburos Metálicos S.A. (Madrid, Spain) was used as a carrier gas.

An Ultrasonic bath P-Selecta Precisterm (Barcelona, Spain), a rotary evaporator system Heildoph VV 2000 (Schwabach, Germany) and PTFE filters (13 mm, $0.5 \mu \mathrm{m})$ (Gloucestershire, UK) were used for sample preparation. Silica C18 cartridges (SUPELCO, Bellefonte, PA, USA) were used to optimize sample clean up.

\subsection{Reagents}

The PCBs solid-liquid extraction was undertaken using high purity n-Hexane ultra-trace analysis (99.6\%) supplied by Scharlau (Barcelona, Spain). Other solvents used to optimize the extraction process, including methanol, ethanol and dichloromethane were supplied by Sigma Aldrich (St. Louis, USA).

\subsection{Standards}

Five representative Aroclors 1016, 1242, 1248, 1254 and 1260 solutions at a concentration level of $1000 \mu \mathrm{g} / \mathrm{mL}$ in isooctane were supplied by SUPELCO (Bellefonte, PA, USA); fresh working solutions were prepared by suitable dilution in n-hexane. The Calibration graph was obtained by the external standard method from solutions in the 17
- $500 \mathrm{ng} / \mu \mathrm{L}$ concentration range. Working solutions were stored at $4^{\circ} \mathrm{C}$.

\subsection{Samples}

Automotive shredder samples were collected at an automotive residue industry; a scheme of the automotive residue recycling is showed in Figure 1. A representative sample of one kilogram was collected every two days for a period of 30 days to obtain about $12 \mathrm{~kg}$. This raw sample was spread homogeneously on a clean surface (20 $35 \mathrm{~g} \cdot \mathrm{dm}^{-2}$ ) and divided into quarters, discarding two opposite quarters, mixing the remaining ones and repeating the process several times, thus reducing the sample to less than one kilogram. This subsample was ground to obtain a maximum particle of about $4 \mathrm{~mm}$ as a stock sample from which the analytical sample was taken. The following five samples of differing size were analyzed as showed in Table 1.

\subsection{Aroclors Solid-Liquid Extraction from the Organic Shredder Sample}

About $0.5 \mathrm{~g}$ of the ground sample was weighed accurately and transferred into a $20 \mathrm{~mL}$ extraction screw tube; then, $10 \mathrm{~mL}$ of $\mathrm{n}$-Hexane were added to the tube. Subsequently the top vial was covered with an aluminium foil and the tube was shaken during 40 minutes in the ultrasonic bath. Afterwards, the mixture was left to stand and the extract was transferred into an evaporating tube, suitable for the rotary evaporator system. The extracting process was repeated by adding another $10 \mathrm{~mL}$ of $\mathrm{n}$ Hexane to the above residue and the tube was shaken during 10 minutes in the ultrasonic bath; the new extract was transferred into the same evaporation tube as before Combined extracts were evaporated in the rotary evaporator system up to $2 \mathrm{~mL}$ before being transferred to a conical evaporation tube where the volume was reduced to $0.3 \mathrm{~mL}$ by blowing an Argon flow. This final volume was filtered through a PTFE filter, transferred to a topaz crimp top vial, and stored at $4^{\circ} \mathrm{C}$ before analysis by GC/MS

Table 1. Particle size samples analyzed.

\begin{tabular}{cc}
\hline Sample & Particle size \\
\hline A & $2 \mathrm{~mm}$ \\
B & $1 \mathrm{~mm}$ \\
C & $2 \mathrm{~mm}$ \\
D & $1 \mathrm{~mm}$ \\
E & $4 \mathrm{~mm}$ \\
\hline
\end{tabular}




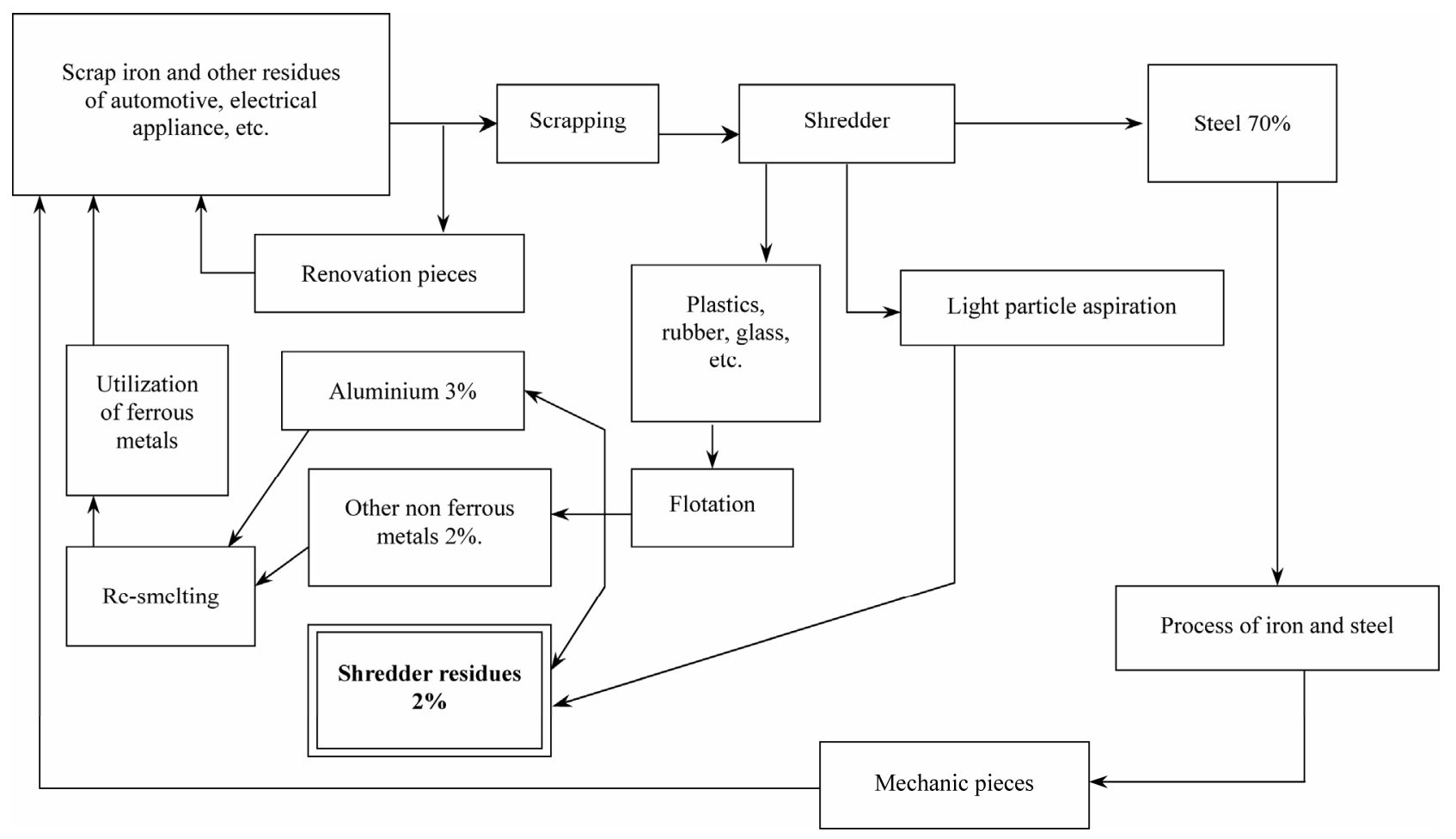

Figure 1. Automotive residue recycling process.

\subsection{Chromatographic Method}

One microliter of the above prepared analytical solution was injected into the gas chromatograph in splitless mode during 1 minute. The following temperature program was applied: injector temperature, $250^{\circ} \mathrm{C}$; initial oven temperature, $80^{\circ} \mathrm{C}$ during $4 \mathrm{~min}$, then a $5^{\circ} \mathrm{C} \cdot \mathrm{min}^{-1}$ ramp to $250^{\circ} \mathrm{C}$ was applied standing at this temperature for 5 minutes and then a $10^{\circ} \mathrm{C} \cdot \mathrm{min}^{-1}$ ramp to $280^{\circ} \mathrm{C}$ standing for 19 minutes. Interface temperature was $280^{\circ} \mathrm{C}$; electronic impact ionization source temperature was $250^{\circ} \mathrm{C}$ and the potential between the filament and the anode was $70 \mathrm{eV}$; scan masses range was from 50 to 800 amu in total ion chromatogram mode. The background signal over which Aroclors chromatographic peaks appear was eliminated by subtracting lineal aliphatic hydrocarbons mass spectra background. Then, 256, 292 and 326 ion masses were selected to quantify PCBs and integrated chromatographic peak areas containing these masses were combined and used as a total area.

\section{Results and Discussion}

\subsection{Selection of Common Ion Masses}

In order to facilitate the detection of ion masses which are common to all PCBs, different chromatographic conditions were tested to achieve adequate chromatographic separation; for this purpose, the AROCLOR 1254 stan- dard solution was analyzed in several chromatographic conditions; programmed temperature was used in all tests; the injector temperature was changed in the range $250^{\circ} \mathrm{C}$ - $280^{\circ} \mathrm{C}$ and different starting temperatures and ramps were tested; the best experimental conditions, which are specified in Section 2.6, were chosen and chromatograms of selected Aroclors were obtained. In all of them, 256, 292 and $326 \mathrm{~m} / \mathrm{z}$ ion masses are present, corresponding to biphenyl-trichloro, biphenyl-tetrachloro and biphenylpentachloro, respectively (Figure 2); in order to quantify PCBs content as a whole, total integrated area of chromatographic peaks containing these ions was used.

The standard calibration was obtained using the Aroclor 1254 standard solution between 17 and $500 \mathrm{ng} / \mu \mathrm{L}$; results and relevant data are showed in Table 2. Three standard solutions of $170 \mathrm{ng} / \mu \mathrm{L}$ concentration were analyzed to determine method precision and reproducibility; results are showed in Table 2.

\subsection{Optimization of the PCBs Solid-Liquid Extraction Process}

The B sample was enriched with $100 \mu \mathrm{L}$ of Aroclor 1254 and variation of total PCBs area was taken for optimization purposes; extraction solvent, agitation time and other solid-liquid extraction conditions were studied.

Different extraction solvents including n-hexane, methanol, dichloromethane and n-hexane:ethanol (70:30; v:v) 


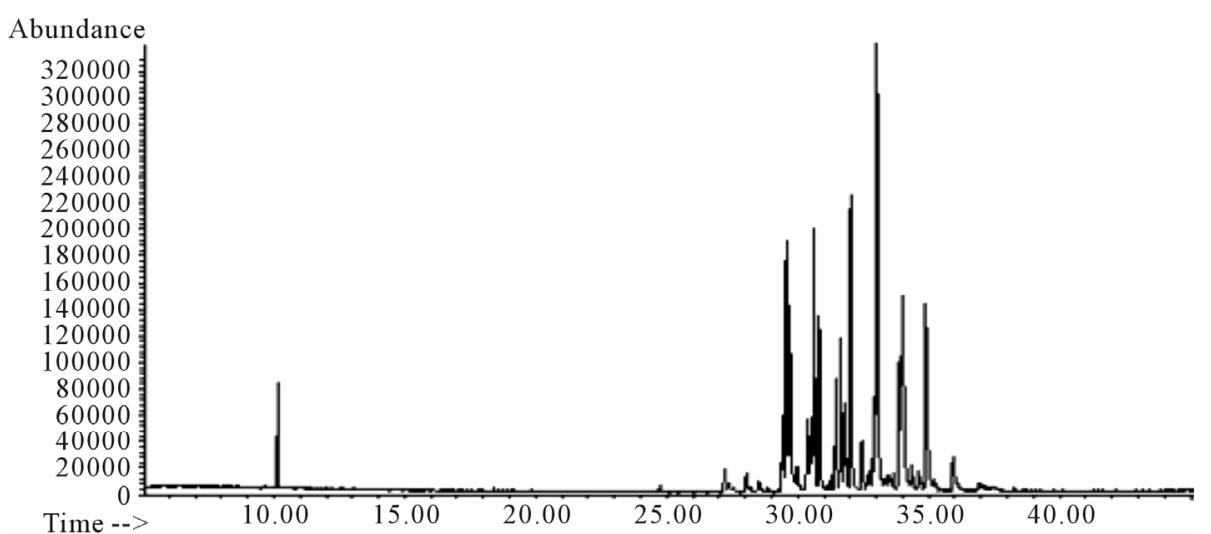

(a)

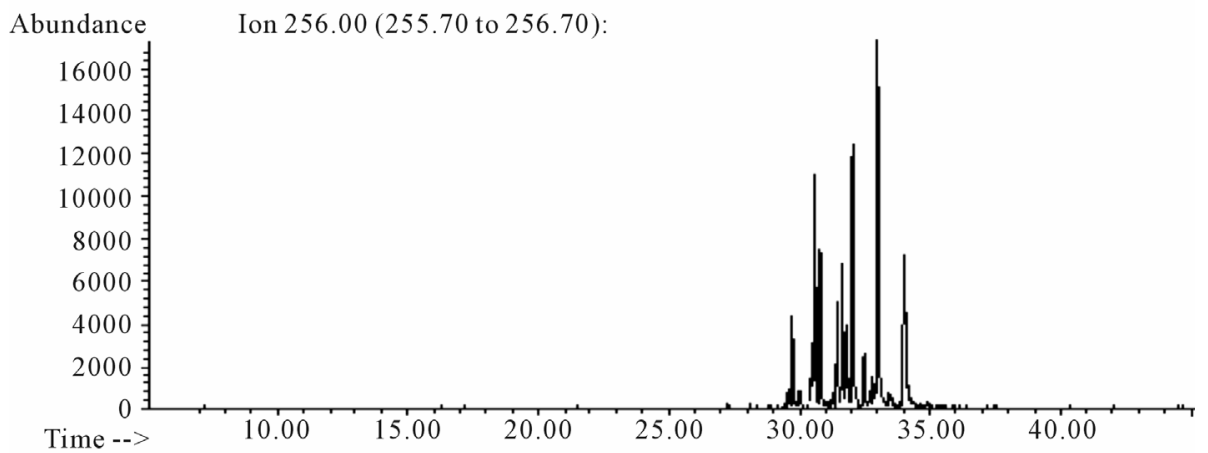

(b)

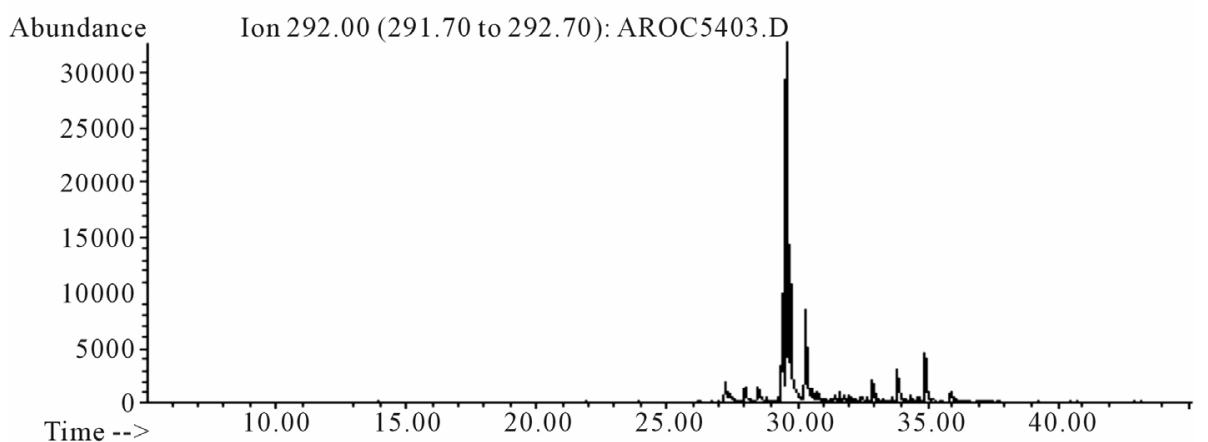

(c)

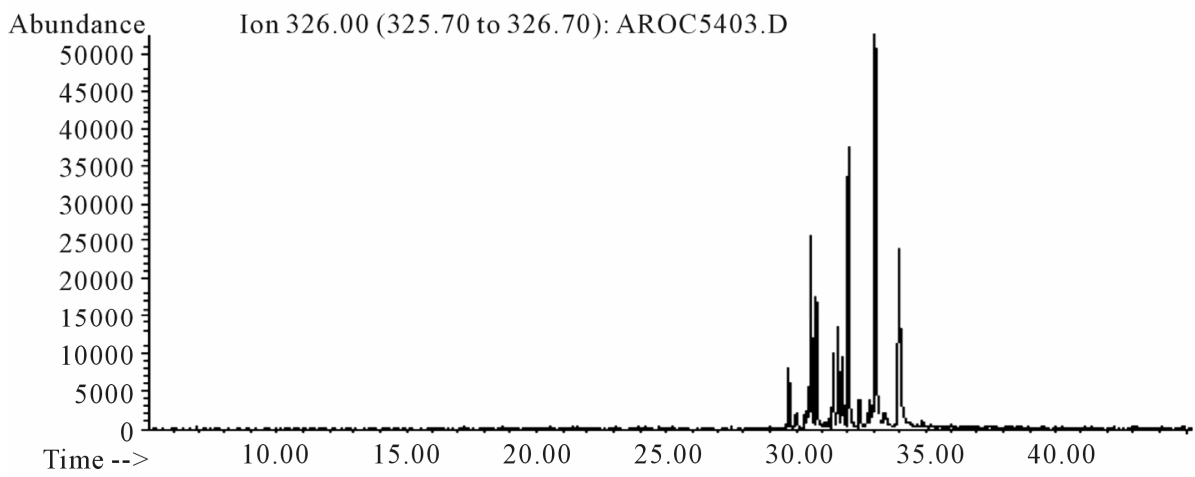

(d)

Figure 2. (a) Total ion chromatogram of AROCLOR 1254 standard solution; (b) Chromatogram obtained selecting 256 ion mass selected; (c) Chromatogram obtained selecting 292 ion mass selected; (d) Chromatogram obtained selecting 326 ion masses selected. 
as well as different volumes and agitation times were tested; best results were found using n-hexane in two successive portions of $10 \mathrm{~mL}$ each, with agitation in an ultrasonic bath during 40 minutes for the first solvent portion and 10 minutes for the second one. A chromatogram obtained from this extract is showed in Figure 3; it can be seen that the typical unresolved lineal aliphatic hydrocarbons concave shape background appears, over which PCBs chromatographic peaks are detected. Consequently, a clean up by solid phase extraction using silica $\mathrm{C} 18$ cartridges was used, applying the protocol of $\mathrm{M}$. M. Schantza et al. [14]; however, PCBs recoveries were quite low, indicating difficulties in separating PCBs from hydrocarbons efficiently. Therefore, a methodology was applied based on background subtraction of mass spectra over which selected PCBs ion masses appear. This background spectrum consisted of lineal aliphatic hydrocarbons (Figure 4) and it was common to the whole retention time range in which PCB peaks appear in the total ion chromatogram. When this hydrocarbon massspectra was subtracted, using the Hewlett-Packard Chemstation B.02.05 software with GC/MS Engine instrument, from the total ion chromatogram, the new chromatogram is showed in Figure 5; it can be seen that most of the initial background was eliminated. Over this clean chromatogram, common ion masses of PCBs (256, 292 and 326 $\mathrm{m} / \mathrm{z}$ ) were selected and chromatographic peaks were integrated on a chromatogram of these selected masses. This chromatogram is showed in Figure 6.

\subsection{Analysis of Automotive Shredder Samples}

The procedure specified in the experimental chapter was applied to samples from an automotive shredder industry detailed in Table 1. Results obtained are showed in Table 3; as can be seen, PCBs were detected in all samples; the highest concentration detected was in sample B. In any case these PCBs content should be taken into account in order to be used as a combustion fuel in cemetery industry.

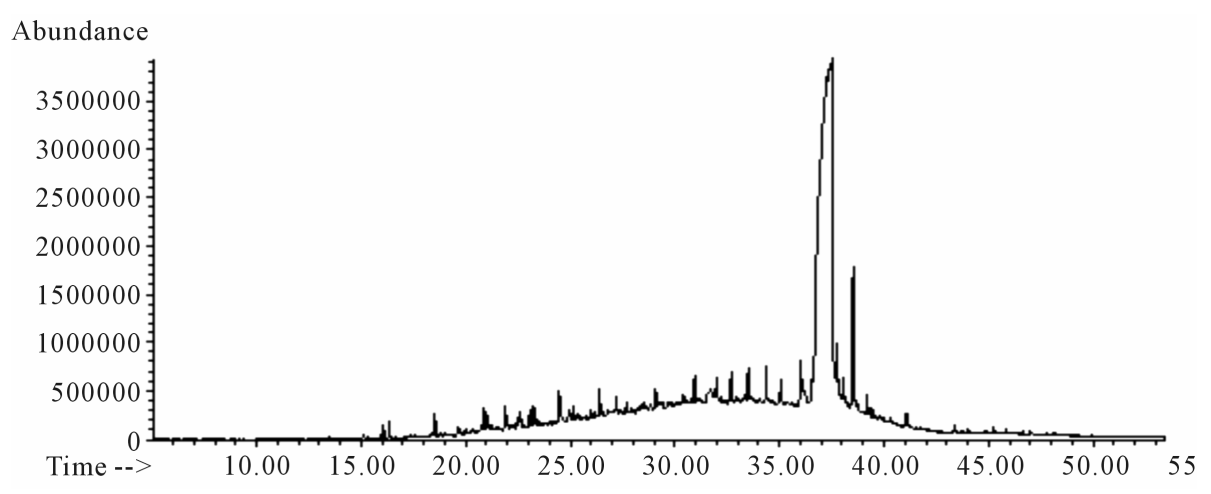

Figure 3. Total ion chromatogram of B sample enriched with $100 \mu \mathrm{L}$ of AROCLOR 1254.

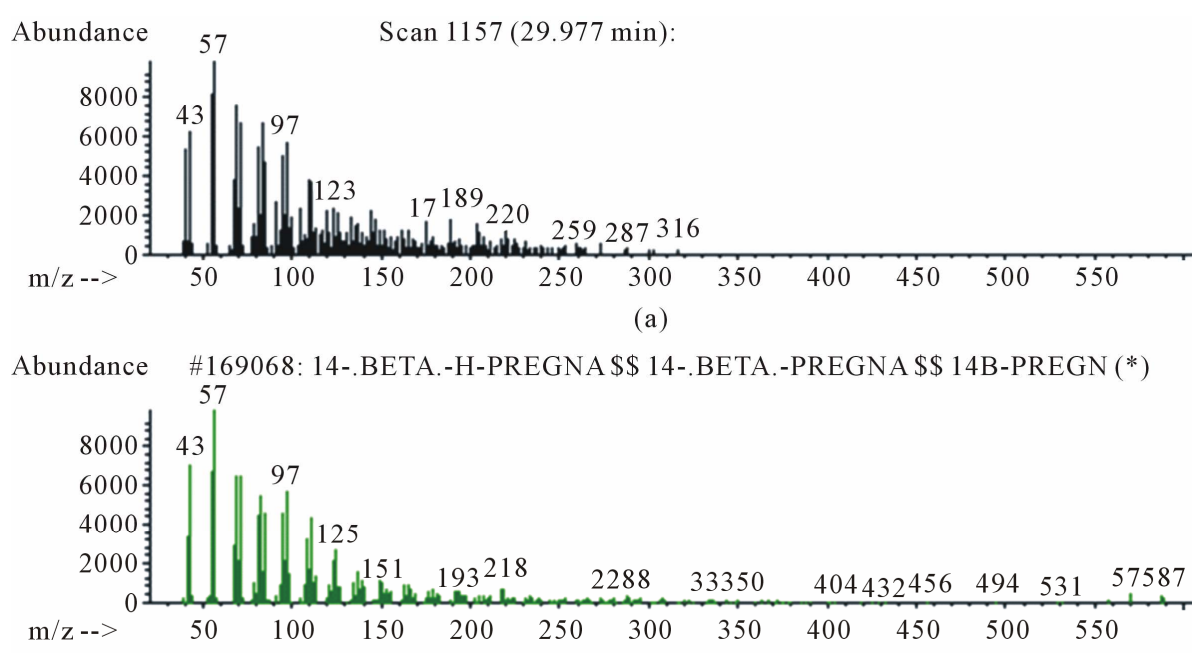

(b)

Figure 4. Mass spectra of B sample analysis: (a) Mass spectra of concave shape background obtained in B sample analysis 
enriched with $100 \mu \mathrm{L}$ of AROCLOR; (b) Identification by WILLEY library of background.

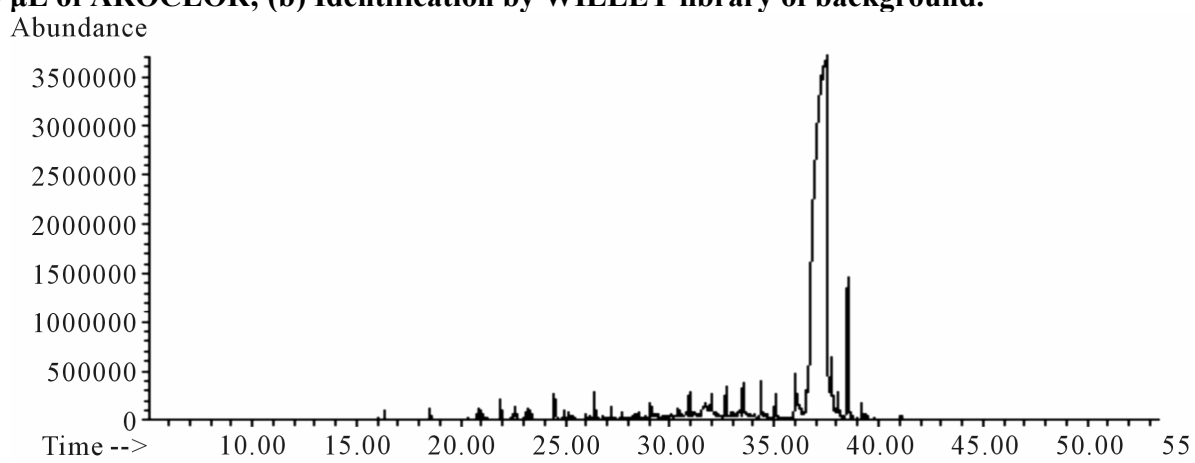

Figure 5. Total ion chromatogram of B sample subtracting background of the lineal aliphatic hydrocarbon interferences.

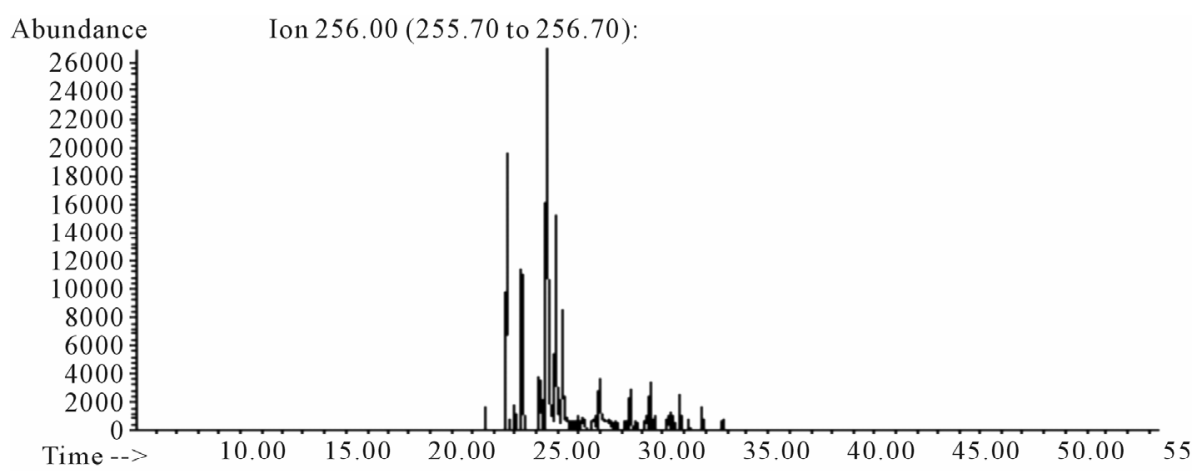

(a)

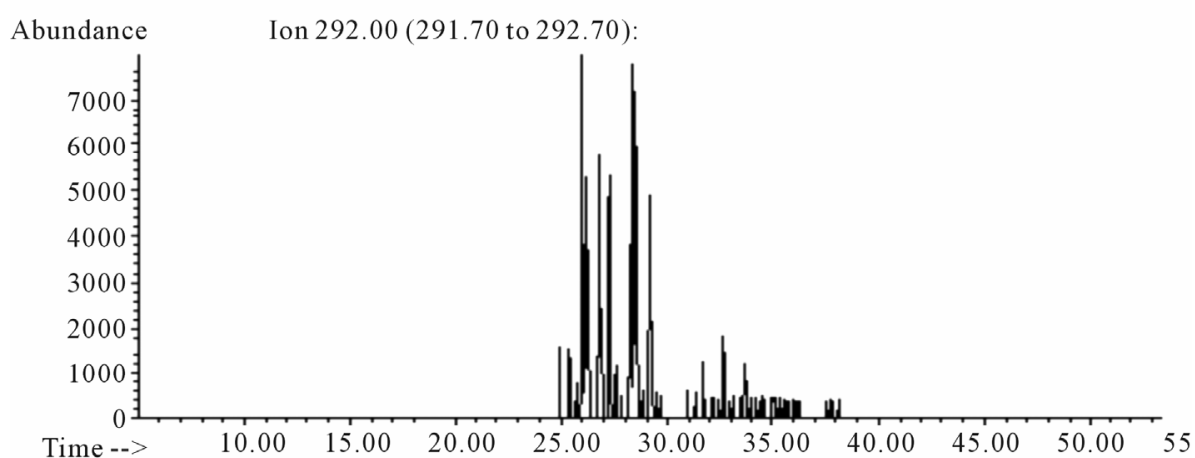

(b)

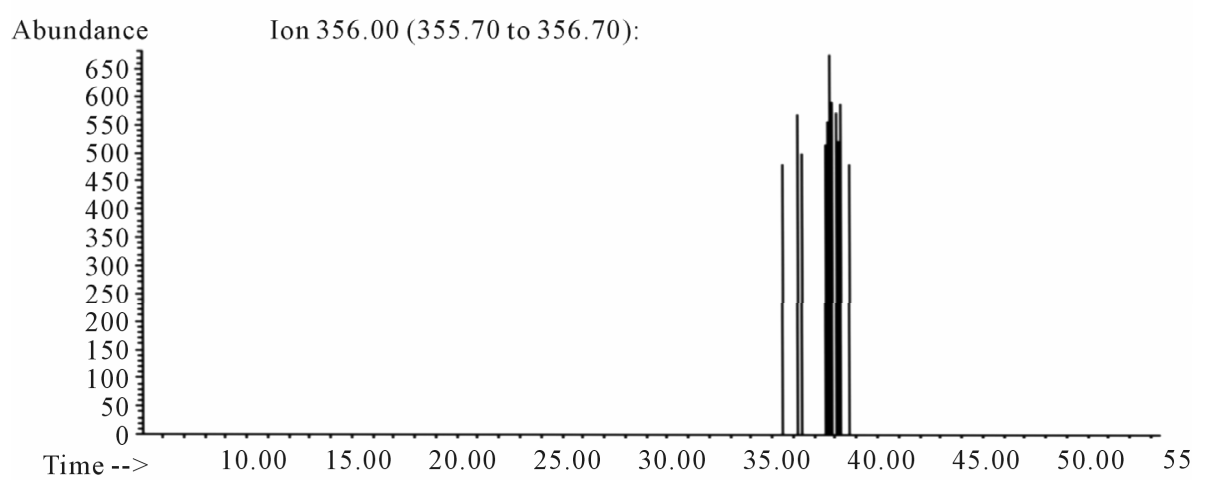

(c)

Figure 6. Total ion chromatogram obtained of sample B sample analysis: (a) Chromatogram obtained selecting 256 ion mass selected; (b) Chromatogram obtained selecting 292 ion mass selected; (c) Chromatogram obtained selecting 326 ion masses 
selected.

\subsection{Recovery Study}

Because shredder reference samples were not available, recovery was determined to establish the validity of the proposed method. For this purpose, different volumes in the range of $25-100 \mu \mathrm{L}$ of Aroclor 1254 were added to the sample and analyzed by following the same procedure as for samples. Results are showed in Table 4.

\section{Conclusions}

A direct method to identify and quantify PCBs in automotive shredder industry samples was proposed. The use of three selected ion masses $(256,292$ and $326 \mathrm{~m} / \mathrm{z}$ )

Table 2. Standard calibration results.

\begin{tabular}{cc}
\hline $\begin{array}{c}\text { Calibration graph equation } \\
\text { Regression coefficient }\end{array}$ & Total area $=8.68104 \mathrm{C}-1127398.1$ \\
${ }^{*}$ RSD & \\
& \\
Sensitivity & ${ }^{* *}$ L.D. $=3 \cdot[.05 \%$ \\
& ${ }^{* *}$ L.D. $\left.=(\mathrm{S} / \mathrm{N} / \mathrm{N}) / \mathrm{m}\right]=0.16 \mathrm{mg} / \mu \mathrm{L}$ \\
\hline
\end{tabular}

${ }^{*}$ RSD, Relative Standard Deviation; ${ }^{* *}$ L.D., Limit Detection.

Table 3. PCBs concentrations detected in automotive shredder samples.

\begin{tabular}{ccc}
\hline${ }^{*}$ Samples & Caverage, $\mu \mathrm{g} / \mathrm{g}$ & ${ }^{* *} \mathrm{RSD}, \%$ \\
\hline A & 116 & 21 \\
B & 191 & 24 \\
C & 118 & 22 \\
D & 94 & 12 \\
E & 102 & 23 \\
\hline
\end{tabular}

*0.5 g weight samples; ${ }^{* *} \mathrm{RSD}$, Relative Standard Deviation.

Table 4. Results obtained in recovery study in B and C samples.

\begin{tabular}{cccccc}
\hline \multicolumn{5}{c}{ PCBs, $\mu \mathrm{g}$} \\
\hline $\begin{array}{c}\text { Sample } \\
\text { Weight, g }\end{array}$ & $\begin{array}{c}\text { Sample } \\
\text { Content }\end{array}$ & Added & Found & ${ }^{*} \mathrm{R} \%$ & ${ }^{* *} \mathrm{RSD}$ \\
\hline & & 25 & 80 & 119 & 14 \\
B 0.5 & 51 & 50 & 108 & 116 & 11 \\
& & 100 & 134 & 84 & 20 \\
\hline C 0.5 & 47 & 50 & 101 & 104 & 11 \\
& & 100 & 125 & 85 & 15 \\
\hline
\end{tabular}

"R, Recovery; **RSD, Relative Standard Deviation for $\mathrm{n}=3$.

which are present in all commercial Aroclors, making for an easy and fast method, was carried out in complex industry samples, without the need for high resolution Recovery results show the validity of the method. For this reason, a simple solid-liquid extraction process of PCBs and then their analysis by GC/MS is enough to conclude the presence or absence of these compounds in automotive shredder samples which could be used in recycled materials.

This method could be applied to other types of solid samples in order to conclude the presence or absence of PCBs.

\section{Acknowledgements}

This article would have been impossible without the equipment and materials contributed by CAI-UEM, Research Support Centre-Mass Spectrometry Unit, University Complutense of Madrid

\section{REFERENCES}

[1] J. Péra, J. Ambroise, M. Chabannet, "Valorization of Automotive Shredder Residue in Building Materials," Cement and Concrete Research, Vol. 34, No. 4, 2004, pp. 557-562.

[2] K. J. Kima, D. Kima, S. H. Choia, K. Chunga, K. S. Shina, F. Barlatb, K. H. Oha and J. R. Youn, "Formability of AA5182/Polypropylene/AA5182 Sandwich Sheets," Journal of Materials Processing Technology, Vol. 139, No. 1-3, 2003, pp. 1-3. doi:10.1016/S0924-0136(03)00173-0

[3] J. A. S. Williams, S. Wongweragiat, X. Qu, J. B. McGlinch, W. Bonawi-tan, J. K. Choi and J. Schiff, "An Automotive Bulk Recycling Planning Model," Journal of Operational Research, Vol. 177, No. 2, 2007, pp. 969981.

[4] Börjeson, L. Börjeson, G. Löfvenius, M. Hjelt, S. Johansson and S. Marklund, "Characterization of Automotive Shredder Residues from Two Shredding Facilities with Different Refining Processes in Sweden," Waste Management and Research, Vol. 18, 2000, pp. 358-366.

[5] B. Heinzow, S. Mohr, G. Ostendorp, M. Kerst and W. Körner, "PCB and Dioxin-Like PCB in Indoor Air of Public Buildings Contaminated with Different PCB Sources-Deriving Toxicity Equivalent Concentrations from Standard PCB Congeners," Chemosphere, Vol. 67, No. 9, 2007, pp. 1746-1753. doi:10.1016/j.chemosphere.2006.05.120

[6] A. J. Pedersen and L. M. Ottosen, "Elemental Analysis of Ash Residue from Combustion of CCA Treated Wood Waste before and after Electrodialytic Extraction," Chemosphere, Vol. 65, No. 1, 2006, pp. 110-116. doi:10.1016/j.chemosphere.2006.02.021 
[7] B. Colin, "Enviromental Chemistry," Freeman, pp. 252272.

[8] H. T. Joung, Y. C. Seo, K. H. Kim and Y. C. Seo, "Effects of Oxygen, Catalyst and PVC on the Formation of PCDDs, PCDFs and Dioxin-Like PCBs in Pyrolysis Products of Automobile Residues," Chemosphere, Vol. 65, No. 9, 2006, pp. 1481-1489. doi:10.1016/i.chemosphere.2006.04.018

[9] S. Lorán, S. Bayarri, P. Conchello and A. Herrera, "Risk Assessment of PCDD/PCDFs and Indicator PCBs Contamination in Spanish Commercial Baby Food," Food and Chemical Toxicology, Vol. 48, No. 1, 2009, pp. 145151. doi:10.1016/j.fct.2009.09.031

[10] S. L. Wang, C. Y. Lin, Y. L. Guo, L. Y. Lin, W. L. Chou, L. W. Chang, "Infant Exposure to Polychlorinated Dibenzo-p-Dioxins, Dibenzofurans and Biphenyls (PCDD/Fs, PCBs) - Correlation between Prenatal and Postnatal Exposure," Chemosphere, Vol. 54, No. 10, 2004, pp. 14591473. doi:10.1016/j.chemosphere.2003.08.012

[11] S. Jursa, J. Chovancová, J. Petrík and J. Lokša, "Dioxin-Like and Non-Dioxin-Like PCBs in Human Serum of Slovak Population," Chemosphere, Vol. 64, No. 4, 2006, pp. 686-691. doi:10.1016/j.chemosphere.2005.10.048

[12] T. Takasuga, K. Senthilkumar, T. Matsumura, K. Shiozaki and S. Sakai, "Isotope Dilution Analysis of Polychlorinated Biphenyls (PCBs) in Transformer Oil and Global Commercial PCB Formulations by High Resolution Gas Chromatography-High Resolution Mass Spectrometry," Chemosphere, Vol. 62, No. 3, 2006, pp. 469484. doi:10.1016/j.chemosphere.2005.04.034

[13] M. Ren, P. A. Peng, S. K. Zhang, Y. Y. Deng, B. X. Mai, G. Y. Sheng and J. M. Fu, "Determination of 2,3,7,8Substitituted Polychlorinated Dibenzo-p-dioxins-dibenzofurans and Dioxin-Like Polychlorinated Biphenyls in Environmental Samples by Gas Chromatography/High Resolution Mass Spectrometry," Chinese Journal of Analytical Chemistry, Vol. 35, No. 2, 2007, pp. 176-180. doi:10.1016/S1872-2040(07)60033-4

[14] M. M. Schantza, S. Bøwadt, B. A. Benner, S. A. Wisea and S. B. Hawthorneb, "Comparison of Supercritical Fluid Extraction and Soxhlet Extraction for the Determination of Polychlorinated Biphenyls in Environmental Matrix Standard Reference Materials," Journal of Chromatography A, Vol. 816, No. 2, 1998, pp. 213-220. 